\title{
Stress of Medical Practitioners in Private Healthcare Industry
}

\author{
Hassan Danial Aslam ${ }^{1}$, Rossilah Jamil ${ }^{2}$ \& Amber Tariq ${ }^{1}$ \\ ${ }^{1}$ Faculty of Management Sciences, Department of Management Sciences, The Islamia University of Bahawalpur, \\ Pakistan \\ ${ }^{2}$ International Business School, Universiti Teknologi Malaysia, Kuala Lumpur, Malaysia \\ Correspondence: Rossilah Jamil, International Business School, Universiti Teknologi Malaysia, Level 10, Razak \\ Tower, Universiti Teknologi Malaysia Kuala Lumpur, Jalan Semarak, 54100 Kuala Lumpur, Malaysia. Tel: \\ 60-33-2180-5050. E-mail: rosillah@ibs.utm.my
}

Received: July 9, 2014 Accepted: September 18, 2014 Online Published: October 30, 2014

doi:10.5539/ass.v10n22p111 URL: http://dx.doi.org/10.5539/ass.v10n22p111

\begin{abstract}
Stress is a universal and inevitable component of life. The article reports findings of a study aimed to determine the sources of stress among medical practitioners in private hospitals. The context of the study is medical practitioners in private hospitals and clinics in Bahawalpur, Pakistan. Field study was conducted and primary data collection instrument was questionnaires. The questionnaire was based on five dimensions: workload, working conditions, role overload, sleep deprivation and unrealistic demands of the patients. The data was analyzed through statistical techniques using SPSS Version 16. Findings of the study revealed that sleep deprivation was the most important source of stress, followed by workload, working conditions, role overload and unrealistic demands of patients. The study provides a piece of evidence which may be used to illustrate the stress level of private practitioners in the healthcare industry in a developing country. Results of this study are useful to guide and inform healthcare management and policy measures.
\end{abstract}

Keywords: doctors, healthcare, occupational stress, Pakistan, private hospitals, source of stress

\section{Introduction}

One of the most stressful occupations is healthcare practitioners (Aziz, 2004) due to their significant impact on human life (Rees, 1995). A cross-sectional and longitudinal study confirms that doctors experienced stress much above the threshold level compared to the general working population (Firth-Cozens, 2003). Studies have shown stress adversely impacts the physical and psychological well-beings of doctors (Burke \& Deszca, 1986; Sonneck \& Wagner, 1996). Considerable work has been done in the area of stress among healthcare practitioners throughout the world. However, most have focused in the European countries and very few have investigated the issue in Pakistan. It is widely acknowledged that developing countries lack appropriate standards and working conditions to ensure work-life balance. As such, this triggers the selection of Pakistan. The prime concern of the study was to reveal the true side job stress among doctors in Pakistan. Bahawalpur region was chosen as a representative city because it is one of the least developed regions in Pakistan in terms of working conditions and living standards. Findings originating from this context would contribute to management and policy suggestions. This topic is significant because of it leads to better provision of health services to general public which should be a very basic necessity in life. Against this backdrop, a study was conducted to investigate the sources and causes of stress among doctors in hospitals in Pakistan with a specific focus on those working in the private healthcare providers located in the region of Bahawalpur.

\section{Literature Review}

Stress is defined as an 'adaptive response to a situation that is perceived as challenging or threatening to a person's well-being' (McShane \& Glinow, 2010, p. 114). It is a result of the physical, mental and emotional strains exposed to a person due to his / her surrounding environment that exceeds his/her capacities to adapt. Stress occurs when there is an imbalance between demands and resources and an individual surpasses his / her professed ability to manage (Lazarus \& Folkman, 1984). Research shows that work stress is a global phenomenon affecting the working population in North America, Europe and Asia (McShane \& Glinow, 2010). Stress can be categorized into positive stress (i.e. distress) and negative stress (i.e. eustress) (ibid.). Long exposure to negative stress often results to job burnout which involves gradual emotional exhaustion, cynicism 
and loss of personal accomplishment (Maslach et al., 2001). Negative stress has been a major concern both in research and practice due to its adverse consequences to individuals and organizations.

Doctors are facing an increased pressure which directly impacts their performance (Caplan, 1994). Some of the factors that make doctor's life seriously stressful are the long hours, dealing with critically-ill patients, emergency and night calls, sustaining medical education and personal development, and aspiring for higher goals attainment (Shiwani, 2009). The stress will further worsen when the work environment provides lack of control over work environment, job recognition, inflexible organization structure, and monetary reward (Imtiaz \& Ahmad, 2009). Lower job satisfaction and abandoning work owing to stress was highly complained by physicians and surgeons (Anthony, 2001). Stress may depend on the type of medical practice. Doctors who work in hospitals were found to experience higher levels of stress than those working in other healthcare areas such as private clinics (Lim \& Pinto, 2009). Tyson and Pongruengphant (2004) in their 5-year longitudinal study involving in 14 private and public hospitals in Thailand conclude that those working in public hospitals generally reported more stress than their counterpart in the private hospitals. However, an earlier study by Tyler et al. (1991) found that nurses in both practices reported similar high level of stress. A decade-long of literature review shows that stress-related and mental disorder among doctors in China is highly prevalent particularly for public hospital doctors (Chen et al., 2013). The causes listed include workload, highly demanding patients, occupational risks, effort-reward imbalance and highly-competitive environment for promotion. Addiction to opioids remains the most common substance abuse among doctors particularly anesthesiologists (Bryson \& Silverstein, 2008). Brooke et al. (1993) revealed that depression mainly due to work stress was one of the most frequent pathways leading to substance abuse among doctors.

The cause of stress (i.e. stressors) among doctors is a widely-researched topic (e.g. Maslach et al., 2001; Gray-Tofta \& Anderson, 2002). Wong (2008) enlisted that doctor stress is caused by five factors: 1) job itself, the organization; 2) personal factors; 3) relationship with others; and 5) work-life balance. On a similar note, McShane \& Glinow (2010) highlighted three most common stressors being: 1) harassment and incivility in the workplace; 2) work overload; and 3) low task control. Knowledge derived from the literature is used to develop the following research theoretical framework (Figure 1).

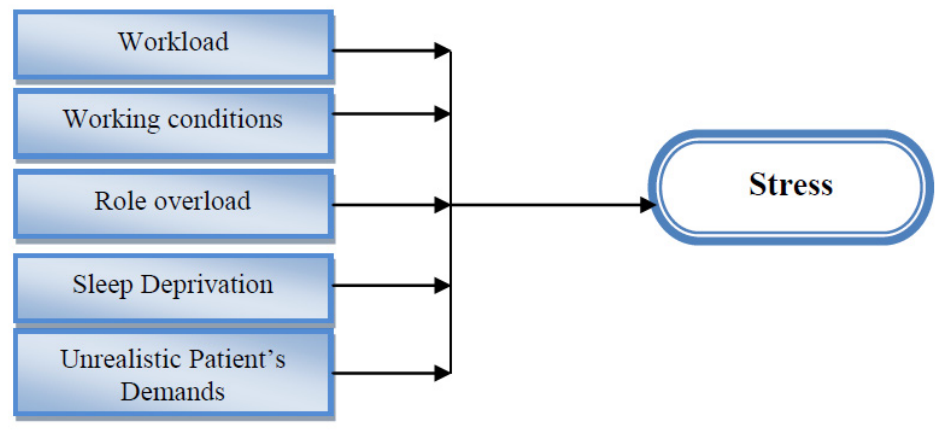

Figure 1. Model measuring the stress level among doctors

The first factor, workload, refers to the amount of hours and efforts required to perform tasks. The importance of this factor as a contributor to job stress among medical practitioners has been found by previous researchers such as Smith (2001), Happel et al. (2013), Gray-Tofta and Anderson (2002), Aziz (2004), and McGowan et al. (2013). Excessive workload reduces productivity and leads to stress. The second factor, working conditions, refers to various job relevant factors that directly or indirectly affect the job performance. These include basic pay, job hours, health and job security, recognition, benefits, and organizational culture and climate. Negative working conditions are detrimental to personal and organizational well-beings (Kaur et al., 2009; Khuwaja et al., 2004). For instance, unsupportive workplace climate (Happel et al., 2013) and depressing relationships with other doctors (Branthwaite \& Ross, 1988) has been found as causes of doctor's stress. Right working condition is crucial since it affects practitioners' job satisfactions and consequently the service they provide to patients (Stanowski, 2009). Thirdly, role overload refers to the extent to which an individual regards him or herself being pressured due to multiple commitments and responsibilities (Reilly, 1982). It includes professional and personal life roles. Role overload contributes to an increased workload. Role overload is different from role conflict and role ambiguity. Role overload as an important contributor to job stress has been found by previous researchers such as Branthwaite and Ross (1988), Cooper et 
al. (1989) and Maslach et al. (1997). The fourth factor, sleep deprivation is also one of the important sources of stress (Khuwaja et al., 2004; French et al., 2001). This is caused by their long hours and the need to be on-call. A study in Pakistan showed that sleep deprivation is a very common problem among doctors and badly affects their work performance, physical and mental health (Mustahsan et al., 2013). Doctors who did not get enough sleep were more prone in making medical errors, experienced mood-related symptoms, personality changes and other health problems (ibid.). And the fifth factor, unrealistic expectations from patients also a contributor to stress in doctors (Kushnir et al., 1997; D. Bonn \& J. Bonn, 2000; Hayter et al., 1996). Edwards et al. (2002) has given example that patients sometimes expect doctors to spend longer time examining them. Another example includes expecting doctors to completely cure their diseases. From these findings, the following hypotheses are developed. Against the backdrop of these literatures, the following hypotheses are developed:

H0: There is no significant relationship between workload and stress level among doctors.

H1: There is a significant relationship between workload and stress level among doctors.

H0: There is no relationship between working conditions and stress level among doctors.

H1: There is a relationship between working conditions and stress level among doctors.

H0: There is no relationship between role overload and stress level among doctors.

H1: There is a relationship between role overload and stress level among doctors.

H0: There is no relationship between sleep deprivation and stress level among doctors.

H1: There is a relationship between sleep deprivation and stress level among doctors.

H0: There is no relationship between unrealistic patient's demands and stress level among doctors.

H1: There is a relationship between unrealistic patient's demands and stress level among doctors.

\section{Methodology}

The subjects in the present study consisted of doctors and medical practitioners of the private hospitals and clinics in Bahawalpur, Pakistan. The data was collected through survey method in which the questionnaire was mailed to 250 doctors and practitioners. A total of 235 questionnaires were returned in which $223(89 \%)$ were found correct and utilizable. The questionnaire consisted of 24 items representing 5 dimensions of stress: sleep deprivation, work overload, working conditions, role overload and unrealistic patient's demands. Responses were recorded against a five-point Likert scale comprising of $1=$ strongly agree; $2=$ agree; 3=uncertain; $4=$ disagree; $5=$ strongly disagree. The respondents were asked to respond on each of the item and indicate the degree to which each of the items on the questionnaire contributed to stress on the Likert scale. The questionnaire was adapted from Nayak (2008). The result for Cronbach Alpha for the 24 items on the questionnaire determining sources of stress was 0.805 , designating high level of internal consistency of the scale.

\section{Findings and Discussion}

The mean, standard deviation and variance were obtained using SPSS. The highest mean score items were workload (3.124), working environment/conditions of the hospital (3.104), and deprivation of sleep (3.101). The items with lower mean scores were monotonous routine (2.21), norms and expectations (2.13), and unrealistic hopes to the patients (1.91). The analysis of the impact of stress variables on doctors through coefficient of correlation was: workload showed a relatively strong positive significant relationship with stress with correlation value of 0.665 at 0.000 significance value. Working conditions showed a positive significant relationship with stress among doctors with correlation value of 0.589 at 0.000 significance value. Role overload showed a moderately significant relationship with stress with correlation value of 0.512 . Sleep deprivation showed strong positive correlation value of 0.775 . The last dimension unrealistic patient's hopes showed low positive correlation with stress with a value of 0.219 . On the basis of the above results obtained from correlation, our alternate hypothesis $\mathrm{H} 1, \mathrm{H} 2, \mathrm{H} 3, \mathrm{H} 4, \mathrm{H} 5$ are accepted.

Table 1 represents the model summary. The value of $R$ that is the correlation coefficient value is used to measure the linear association between variables. The value of $\mathrm{R}$ in the model summary (Table 1 ) is 0.850 , which shows that there is a strong linear relationship between the variables. $\mathrm{R}$ square is known as coefficient of determination and measures the total variation in the dependent variable that is explained by the relationship with the independent variable. The value of $\mathrm{R}$ square in the model summary is 0.730 which means that the 73.0 percent of the variation in dependent variable (stress) is explained by the relationship between independent variables (workload, working conditions, role overload, sleep deprivation and unrealistic patient's demands). 
Table 1. Model summary ${ }^{\mathrm{b}}$

\begin{tabular}{lllll}
\hline Model & R & R Square & Adjusted R Square & Std. Error of the Estimate \\
\hline 1 & $.850^{\mathrm{a}}$ & .730 & .724 & .47545 \\
\hline
\end{tabular}

Table 2. Analysis of variance ${ }^{\mathbf{b}}$

\begin{tabular}{llllll}
\hline Model & Sum of Squares & df & Mean Square & F & Sig. \\
\hline 1 Regression & 161.783 & 5 & 32.117 & 137.252 & $.000^{\mathrm{a}}$ \\
Residual & 56.289 & 218 & .234 & & \\
Total & 218.072 & 223 & & & \\
\hline
\end{tabular}

a. Predictors: (Constant), Workload, Working Conditions, Role Overload, Sleep Deprivation, Unrealistic Patient's Demand;

b. Dependent Variable: Doctor Stress.

Table 2 highlights the regression results through ANOVA table. F-statistics in the ANOVA table shows a value of 137.252 which means that there is a statistical significance of the relationship between dependent variable and the independent variables when taken in the form of group. It is obtained by dividing the mean square of regression to the mean square of residual. The significance of this value is mentioned in the next column of the ANOVA table that is 0.000 which depicts highly significant relationship.

\section{Discussion}

The study aimed to determine the factors that caused stress in doctors and medical practitioners in private hospitals. The study showed that workload was the most important stressor for the doctors with a mean score value of 3.124 and a correlation value of 0.665 . Based on this the first hypothesis is accepted. The second dimension, working conditions showed a mean score value of 3.104 and correlation value of 0.589 . Hence, the second hypothesis is also accepted. The third dimension, role overload, also showed a positive significant relationship with stress with correlation value of 0.512 , thus, leads to the acceptance of the third hypothesis. Fourthly, sleep deprivation also reported a strong positive correlation value of 0.775 which suggests that the dimension is a strong stressor for the doctors. Lastly, unrealistic patient's demand dimension shows a weak correlation value of 0.219 . This result shows that there is a low positive correlation between unrealistic demands of the patients and stress among doctors. Despite of the weak correlation, the hypothesis H5 is also accepted due to its positive relationship. The study shows that the five dimensions are important stressors of doctors in private doctors in the Bahawalpur region in Pakistan. These findings concur with earlier studies (e.g. Gray-Tofta \& Anderson, 2002; Aziz, 2004; Smith, 2001; Happel et al., 2013; Agdelen et al., 2010; Cooper et al., 1989; Branthwaite \& Ross, 1988; Maslach et al., 1997). Comparatively, this suggests that the stressors of medical practitioners have been somewhat standard and consistent throughout the world regardless of the types of healthcare providers. It is interesting to note that out of the five factors included in the study, unrealistic patient's demand only records a weak correlation value. Since perception towards this factor is most likely stemmed from the kinds of patients that the respondents dealt with, it may be assumed that the respondents covered in the study may not have been exposed to difficult and demanding patients.

\section{Conclusion}

The article has reported findings of a study which aims to identify the sources of stress among medical practitioners in Pakistan with a specific focus of the Bahawalpur region. The study revealed that all five factors contributed to the respondents' stress. Sleep deprivation showed a strong positive correlation with stress (0.775), workload ranked second (0.665), working conditions ranked third (0.589), role overload was fourth with (0.512) and unrealistic patient's demands ranked with a low positive correlation value $(0.219)$. Hence, all alternate hypotheses $\mathrm{H} 1, \mathrm{H} 2, \mathrm{H} 3, \mathrm{H} 4$, and $\mathrm{H} 5$ were accepted. The study provides a piece of evidence to describe the stress level in the context of a developing country. To further understand this issue, future studies can be conducted to explore stress coping strategies among the practitioners. Comparative studies between private and public hospitals in the country are also useful to analyze the what and how stress affects the well-being of the practitioners. Results of this study are useful to guide and inform healthcare management and policy measures. It highlights the actual scenario regarding job stress in the medical profession. Since this group is very prone to job stress, appropriate standards and interventions particularly in those five factors must be implemented by relevant parties to create an environment of healthy work-life balance. Being a developing country, it is understandable 
that lacks of systems and scarcity of talents are common challenges in the nation development. In this landscape, issues such as employee welfare may be easily compromised and fallen into a less priority area. However, it is crucial to remember that this issue should not be taken for granted as stress is a silent killer which directly and indirectly affects the economic and social health of many parties.

\section{References}

Agdelen, Z., Ersoz, B. T., \& Sarp, N. (2010). Working Conditions of the Govermental and Private Hospital Doctors in North Cyprus. International Journal of Pharmaceutical and Healthcare Marketing, 4(2), 191-204. http://dx.doi.org/10.1108/17506121011059786

Anthony, D. (2001). A Survey of Job Satisfaction, Sources of Stress and Psychological Symptoms Among New Zealand Health Professionals. New Zealand Medical Journal, 114, 540-544.

Aziz, A. (2004). Sources of perceived stress among American medical doctors: A cross-cultural perspective. Cross Cultural Management: An International Journal, 11(4), 28-39. http://dx.doi.org/10.1108/1352760 0410797864

Bonn, D., \& Bonn, J. (2000). Work-related stress: Can it be a thing of the past? The Lancet, 355(9198), 124. http://dx.doi.org/10.1016/S0140-6736(05)72040-7

Branthwaite, A., \& Ross, A. (1988). Satisfaction and job stress in general practice. Family practice, 5(2), 83-93. http://dx.doi.org/10.1093/fampra/5.2.83

Brooke, D., Edwards, G., \& Andrews, T. (1993). Doctors and substance misuse: Types of doctors, types of problems. Addiction, 88, 655-663. http://dx.doi.org/10.1111/j.1360-0443.1993.tb02078.x

Bryson, E. O., \& Silverstein, J. H. (2008). Addiction and substance abuse in anesthesiology. Anesthesiology, 109(5), 905-917. http://dx.doi.org/10.1097/ALN.0b013e3181895bc1

Burke, R., \& Deszca, E. (1986). Correlates of psychological burnout phases among police officers. Human Relations, 39, 487-501. http://dx.doi.org/10.1177/001872678603900601

Caplan, R. P. (1994). Stress, Anxiety, and Depression in Hospital Consultants, General Practitioners, and Senior Health Service Managers. BMJ, 1261-1263. http://dx.doi.org/10.1136/bmj.309.6964.1261

Chen, X., Tan, X., \& Li, L. (2013). Health problem and occupational stress among Chinese doctors. Chinese Medicine, 4, 1-6. http://dx.doi.org/10.4236/cm.2013.41001

Cooper, C., Rout, U., \& Faragher, B. (1989). Mental helath, job satisfaction and job stress among general practitioners. BMJ, 298, 366-370. http://dx.doi.org/10.1136/bmj.298.6670.366

Edwards, N., Kornacki, M., \& Silversin, J. (2002). Unhappy doctors: What are the causes and what can be done? BMJ, 324, 835-838. http://dx.doi.org/10.1136/bmj.324.7341.835

Firth-Cozens, J. (2003). Doctors, their wellbeing, and their stress. British Medical Journal, 326(7391), 670-671. http://dx.doi.org/10.1136/bmj.326.7391.670

French, D., Mackinley, R., \& Hastings, A. (2001). GP stress and patient dissatisfaction with nights on call: An exploratory study. Scand J Prim Health Care, 19, 170-173. http://dx.doi.org/10.1080/028134301316982397

Gray-Tofta, P., \& Anderson, J. G. (2002). Stress among hospital nursing staff: Its causes and effects. Social Science \& Medicine. Part A: Medical Psychology \& Medical Sociology.

Happell et al. (2013). Nurses and stress: Recognizing causes and seeking solutions. J. Nurs. Manag., 21(4), 38-47. http://dx.doi.org/10.1111/jonm.12037

Hayter, P., Peckam, S., \& Robinson, R. (1996). Morale in General Practice. Southhampton: Institute for Health Policy Studies, University of Southampton.

Imtiaz, S., \& Ahmad, S. (2009). Impact of stress on employee productivity, performance and turnover: An important managerial issue. International Review of Business Research Papers, 5(4), 468-477.

Kaur, S. S. (2009). A study of job satisfaction and work environment perception among doctors in a tertiary hospital in Delhi. Indian Journal of Medical Science, 63(4), 139-144. http://dx.doi.org/10.4103/0019-5359. 50762

Khuwaja, A. K., Qureshi, R., Andrades, M., Fatmi, Z., \& Khuwaja, N. K. (2004). Comparison of job satisfaction and stress among male and female doctors in teaching hospitals of Karachi. Journal of Ayub Medical College, Abbottabad: JAMC, 16(1), 23-27. 
Kushnir, T., Rabin, S., \& Azulai, S. (1997). A descriptive study of stress management in a group of pediatric oncology nurses. Cancer Nursing, 20(6), 414-421. http://dx.doi.org/10.1097/00002820-199712000-00005

Lazarus, R., \& Folkman, S. (1984). Stress, Appraisal and Coping. New York: Springer.

Lim, R. C. H., \& Pinto, C. (2009). Work stress, satisfaction and burnout in New Zealand radiologists: Comparison of public hospital and private practice in New Zealand. Journal of Medical Imaging and Radiation Oncology, 53(2), 194-199. http://dx.doi.org/10.1111/j.1754-9485.2009.02063.x

Maslach, C., Schaufeli, W. B., \& Leiter, M. P. (2001). Job burnout. Annual Review of Psychology, 52, 397-422. http://dx.doi.org/10.1146/annurev.psych.52.1.397

McGowan, Y., Humphries, N., Burke, H., Conry, M., \& Morgan, K. (2013). Through doctors' eyes: A qualitative study of hospital doctor perspectives on their working conditions. British Journal of Health Psychology, 18(4), 874-891. http://dx.doi.org/10.1111/bjhp.12037

McShane, S. L., \& Glinow, M. A. V. (2010). Organizational Behavior: Emerging Knowledge and Practice for the Real World. Singapore: McGraw Hill.

Mustahsan et al. (2013). Sleep deprivation and its consequences on house officers and postgraduate trainees. Journal of Pakistan Medical Association, 63(4), 540-543.

Nayak, J. (2008). Factors influencing stress and coping strategies among the degree college teachers of Dharwad City, Karnataka. Unpublished master's thesis. University of Agricultural Sciences, Dharwad, India.

Rees, D. (1995). Work-related stress in health service employees. Journal of Managerial Psychology, 10(3), 4-11. http://dx.doi.org/10.1108/02683949510081329

Reilly, M. D. (1982). Working wives and convenience consumption. Journal of Consumer Research, 8, 407-418. http://dx.doi.org/10.1086/208881

Shiwani, M. H. (2009). Health of doctors: A cause of concern. JPMA. The Journal of the Pakistan Medical Association, 59(4), 194-195.

Smith, R. (2001). Why are doctors so unhappy? BMJ, 322(7294), 1073-1074. http://dx.doi.org/10.1136/bmj.322. 7294.1073

Sonneck, G., \& Wagner, R. (1996). Suicide and burnout of physicians. Omega: Journal of Death and Dying, 33, 255-263. http://dx.doi.org/10.2190/0YVL-APPT-NL35-1LXJ

Stanowski, A. (2009). Influencing employees' attitudes and changing behaviors: A model to improve patient satisfaction. Population Health Management, 12(2), 57-59. http://dx.doi.org/10.1089/pop.2009.12201

Tyler, P. A., Carroll, D., \& Cunningham, S. E. (1991). Stress and well-being in nurses: A comparison of the public and private sectors. International Journal of Nursing Studies, 28(2), 125-130. http://dx.doi.org/10. 1016/0020-7489(91)90002-K

Tyson, P. D., \& Pongruengphant, R. (2004). Five-year follow-up study of stress among nurses in public and private hospitals in Thailand. International Journal of Nursing Studies, 41(3), 247-254. http://dx.doi.org/10. 1016/S0020-7489(03)00134-2

Wong, J. (2008). Doctors and stress. Medical Bulletin, 13(6), 4-7.

\section{Copyrights}

Copyright for this article is retained by the author(s), with first publication rights granted to the journal.

This is an open-access article distributed under the terms and conditions of the Creative Commons Attribution license (http://creativecommons.org/licenses/by/3.0/). 